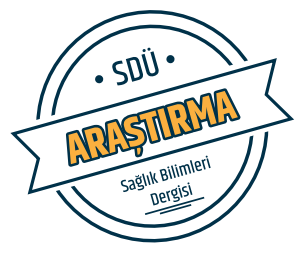

Sdü Sağlık Bilimleri Enstitüsü Dergisi / Cilt 9 Sayı 1 / 2018

\title{
Farklı Dik Yön Boyutlarına Sahip İskeletsel Sınıf I Maloklüzyonlu Bireylerde
} Dentoalveoler Kompanzasyonun İncelenmesi

\section{Examination of Dentoalveolar Compensation Mechanisms in Skeletal Class I Subjects with Different Vertical Skeletal Discrepancy}

\author{
Seylin Mutlu' ${ }^{1}$, Neslihan Ebru Şenışık ${ }^{1}$ \\ ${ }^{1}$ Süleyman Demirel Üniversitesi Diş Hekimliği Fakültesi, Ortodonti AD, Isparta, Türkiye.
}

\begin{abstract}
Özet
Amaç: Bu çalışmanın amacı normal overjet ve overbite' a sahip iskeletsel Sınıf I bireylerde dik yön farklılığının dentoalveoler yapılara ve simfiz morfolojisine etkisi ve doğal vertikal kompanzasyonun incelenmesidir.

Materyal-Metot: $\mathrm{Bu}$ çalıșma vertikal yön açısına göre 3 gruba ayrılmış, her bir alt grupta $15^{\prime}$ er bireyin bulunduğu, Iskeletsel Sinıf I özelliğe sahip toplam 45 birey üzerinde yürütülmüştür. Araştırma gruplarını oluşturan bireylerin tedavi öncesi lateral sefalometrik radyografileri üzerinde belirlenen parametreler doğrultusunda açısal ve milimetrik ölçümler yapılmıștır. Çalıșmada istatistiksel yöntem olarak, varyans analizi (ANOVA) ve Duncan testi kullanılmıştır. Ayrica Pearson korelasyon analizi ile parametreler arasındaki ilişki ortaya konmuştur.

Bulgular: Sınıf I dik yön alt gruplarının karşılaștırılmasında U1/PP, IMPA ölçümleri istatistiksel olarak farklıdır $(\mathrm{p}<0,05)$. $\mathrm{U} 1 / \mathrm{L} 1$ ölçüm değerleri bakımından istatistiksel olarak anlamlı

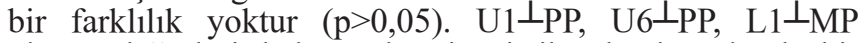
ölçüm değerleri bakımından istatistik olarak anlamlı bir farklılık bulunmaktadır $(\mathrm{p}<0,05)$. Dik yön artışı ile maksiller ve mandibuler anterior dentoalveoler yükseklik artmıştır $(\mathrm{p}<0,01)$. Simfiz ölçümlerinden B'-Pg'-Me, Pg'-Me-Pg, BoMeGo, IdoBoMe bakımından istatistik olarak anlamlı farklılık bulunmaktadır $(\mathrm{p}<0,05)$. Ido-Bo, Bo-Me bakımından istatistiksel olarak anlamlı bir farklılık bulunmuştur $(\mathrm{p}<0,01)$. Sonuç: İdeal overjet ve overbite' 11 farklı dik yön boyutlarına sahip Sınıf I bireylerde, yüzün dik yön boyutları arttıkça alt ve üst keserler kendi kaidelerine göre daha retrüziv konumlanmış ancak keserler-arası açı dik yön değișikliğinden etkilenmemiştir. Sınıf I hiperdiverjan bireylerde simfiz arka yüzeyi daha düz ve sı̆̆ , Sinıf I hipodiverjan bireylerde ise daha eğimlidir. Sınıf I hiperdiverjan bireylerde ön açık kapanış oluşumunun engellenmesinde, simfizin üst yüksekliğindeki artış etkin rol oynamaktadır.
\end{abstract}

Anahtar kelimeler: Dentoalveoler kompanzasyon, vertikal büyüme paterni, sagittal yön anomalisi, simfiz morfolojisi.

\begin{abstract}
Objective: The aim of this study was to examine dentoalveolar compensation and symphysis morphology related to variations in vertical growth direction in skeletal Class 1 individuals.

Material-Method: This study was carried out on a total of 45 individuals with Class I malocclusion who have been divided into three main groups according to their vertical SN/GoGn angles. Angular and lineer measurements were conducted in the direction of the parameters determined on the pretreatment lateral cephalometric radiographs of the subjects constituting the research groups. In statistical analysis, ANOVA (analysis of variance) and Duncan test was used. In addition, the Pearson correlation analysis revealed the relation between the determined parameters.

Results: The difference in U1/PP, IMPA measurements were statistically significant in the comparisons of Class I vertical direction subgroups $(\mathrm{p}<0.05)$. There were no statistically significant difference in U1/L1 measurement $(p>0.05)$. The difference in $\mathrm{U} 1 \perp_{\mathrm{PP}}, \mathrm{U} 6{ }^{\perp}{ }_{\mathrm{PP}}, \mathrm{L} 1 \perp_{\mathrm{MP}}$ measurements were statistically significant $(\mathrm{p}<0.05)$. As the vertical heights increased, maxillary and mandibular anterior dentoalveolar heights also increased $(p<0.01)$. The difference in B'-Pg'$\mathrm{Me}, \mathrm{Pg}$ '-Me-Pg, BoMeGo, IdoBoMe measurements were statistically significant $(p<0.05)$. Statistically significant differences were found for Ido-Bo, Bo-Me measurements $(\mathrm{p}<0.01)$.

Conclusions: In skeletal Class I patients with ideal overjet and overbite, upper and lower incisors were positioned more retruded as the vertical facial heights increased. However interincisal angle was not affected. In hyperdivergent patients, the posterior contour of symphysis was flat, however curved in hypodivergent patients. In class I hyperdivergent individuals, the increase of upper symphyseal height plays an active role in preventing the occurrence of anterior open bite.
\end{abstract}

Keywords: Dentoalveolar compensation, vertical growth pattern, symphysis morphology.

\section{Giriş}

Dengeli bir oklüzyonun meydana gelebilmesi için yüzün büyümesinin miktarını ve yönünü ilgilendiren statik büyüme ile yüzün büyümesinin oranını ve zamanlamasını ilgilendiren dinamik büyümenin senkronizasyonuna ihtiyaç vardır. Yüzün büyüme ve gelişim sürecinde bu iki tip büyümenin eş zamanlı olarak gerçekleşememesi sonucu bölgesel dengesizlikler açığa çıkabilmektedir. Bu bölgesel dengesizlikler, kraniyofasiyal yapının tümünde dengenin yeniden sağlanabilmesi için kompanze edilmeye çalışılır (1). 
Kraniyofasiyal yapının büyüme gelişimi sırasında dişlerin ve alveolar proçeslerin, fonksiyonel oklüzyonu sağlamak üzere dentoalveolar düzeyde meydana getirdiği adaptasyon, doğal dentoalveolar kompanzasyon mekanizması olarak adlandırılmıştır (1,2). Bu mekanizma, büyüme ve gelişimin tamamlanmasıyla uzayın her üç yönündeki çeneler arası iskeletsel uyumsuzluğu -alt ve üst çenelere ait dentoalveoler yapıların şeklini ve konumunu değiștirerek- uzlaşılmış denge konumuna eriştirir. İskeletsel yetersizliği maskeler ve çeneler arası ilişkiyi sağlayan dişlerin, fonksiyonel denge konumuna gelmesini sağlar $(1,3,4)$.

Vertikal yönde dentoalveoler kompanzasyonun incelendiği çalışmalarda normal overbite sağlanması için etkin parametrelerin dentoalveoler yüksekliğin vertikal gelişimi, keser eğimi, maksillanın anterior ve posterior kısmı ve simfizin morfolojisi olduğu bildirilmiștir (2,5-8). Ancak literatürde vertikal yönde dentoalveolar kompanzasyon mekanizmasının incelendiği çalışmalar genellikle, dik yön boyutları artmış olan bireylerde sagittal yön anomalileri göz ardı edilerek, açık kapanış ilişkisi görülen ve görülmeyen bireyleri kıyaslamaya yöneliktir $(3,6,8,9)$. Kraniyofasiyal yapıların sagittal ve vertikal yöndeki ilişkilerinin değerlendirildiği çeşitli çalışmalar ise yüzün sagittal ve vertikal yön büyümelerinin birbirleri ile ilişkili olduğunu bildirmiştir. $\mathrm{Bu}$ nedenle bu iki ayrı büyüme yönüne ait özelliklerin bağımsız olarak değerlendirilmesi yanıltıcı olabilir (10). Bu nedenle dentoalveoler kompanzasyonun mekanizmasını değerlendirebilmek için çeneler arası sagittal ve vertikal yöndeki uyumsuzluğun bir arada ele alınması gerekmektedir. $\mathrm{Bu}$ sebeple bu çalışmanın amacı normal overjet ve overbite' a sahip iskeletsel Sinif 1 bireylerde dik yön farklılığının dentoalveoler yapılara ve simfiz morfolojisine etkisi ve doğal vertikal kompanzasyonun incelenmesidir. Böylece çenelerarası sagittal yön ilişkisi kendi içinde sabitlenecek, farklı dik yön boyutlarında ideal fonksiyonel oklüzyonun sağlanabilmesi için kraniyofasiyal ve dentoalveoler yapıların vertikal yönde ne şekilde adaptasyon gösterdiklerini incelemek ve gruplar arası farklılıklardan yola çıkarak kompanzasyonların nereden kaynaklandığını araştırmak mümkün olabilecektir.

\section{Materyal-Method}

$\mathrm{Bu}$ çalışma için Süleyman Demirel Üniversitesi Tıp Fakültesi Klinik Araştırmalar Etik Kurulu Başkanlığı'ndan 08/07/2014 tarih ve 72867572-050-2374 sayılı kararı ile etik kurul izni alınmıştır. Çalışma kapsamına dâhil edilen bireylerin kronolojik yaşlarının 16-22 yıl arasında olması, lateral sefalometrik radyografilerde izlenen servikal vertebra maturasyonuna göre CS-5 ve üzeri iskeletsel dönemde olması, daha önce ortodontik tedavi görmemiş olması, üst ve alt çenede yer darlığının minimum ya da moderate olması, kraniyofasiyal yapıların gelişimini etkileyebilecek herhangi bir sendrom olmaması, lateral sefalometrik radyografilerinde tespit edilen herhangi bir anatomik deformasyon göstermemesi, kron kaplama veya köprü gibi herhangi bir protetik restorasyonlarının olmaması, yüzde belirgin bir asimetrinin olmaması, üst ve alt çenede daimi ön dişlerinin tamamının sürmüş ve eksiksiz olması, üst ve alt çenede her bir segmentte birden fazla premolar veya molar diş kaybı olmaması, overjet ve overbite ilişkilerinin 1-3 mm arasında olmasına dikkat edilmiştir. 2011-2014 yılları arasında bir üniversitenin Diş Hekimliği Fakültesi Ortodonti Anabilim Dalı'na tedavi amacıyla başvuranlar arasından çalışma kriterlerine uygun iskeletsel Sınıf I hiperdiverjan, normodiverjan ve hipodiverjan $30 \mathrm{k} 1 \mathrm{z} 15$ erkek toplam 45 bireyin tedavi öncesi başlangıç kayıtları araştırma kapsamına dâhil edilmiştir. Araştırma her bir alt grupta $10 \mathrm{k} 1 \mathrm{z}, 5$ erkek toplam $15^{\prime}$ er bireyin bulunduğu 3 gruptaki bireylere ait, toplam 45 lateral sefalometrik radyografi üzerinde yürütülmüştür.

Tüm bireyler anteroposterior yönde $0>\mathrm{ANB}<4$ olarak Sinıf I, vertikal yönde SNGoGn $<27$ ise hipodiverjan, $27>$ SNGoGN $<37$ ise normodiverjan, $\mathrm{SNGoGn}>37$ ise hiperdiverjan olacak şekilde 3 gruba ayrılmıştır. Bireylere ait yaş, ANB, overjet, overbite ölçümlerinin tanımlayıcı istatistiği Tablo 1'de verilmiştir. Araştırma gruplarını oluşturan bireylerden tedavi öncesi standart lateral sefalometrik radyografiler alınmıştır.(Vatech PAX400 digital sefalometrik X-ray cihazı, Amerika). Lateral sefalometrik radyograflar dişler sentrik okluzyonda dudaklar istirahat halinde iken standart şartlarda alınmıştır. Daha sonra DICOM formatında alınan radyografiler Adobe Photoshop CS2 (Adobe Systems San Jose, California, USA) grafik yazılımı ile 1:1 oranında yeniden boyutlandırılmış, uygun renk ve kontrast ayarları yapılarak ideal baskı kalitesine göre ayarlanmıştır. Digital radyografiler kuru baskı lazer yazıcı cihazı (DryPro Model 832, Konica Minolta, Osaka, Japan) kullanılarak özel radyograf kâğıdına (Medical Film Dry Pro SD-P, Konica Minolta, Osaka, Japan) bastırılmıştır. Böylelikle direkt dijital yöntemle alınan radyografilerden 45 adet konvansiyonel radyografi elde edilmiş, lateral sefalometrik radyograflar üzerinde bilinen yöntemlerle bir araştırıcı (SM) tarafından iskeletsel, dişsel ve simfiz ölçümler gerçekleştirilmiştir (Şekil 1-4).

Tablo 1. Öğrencilerin Sosyo-Demografik Özellikleri (n: 22)

\begin{tabular}{lcccc}
\hline \multirow{2}{*}{$\begin{array}{l}\text { SINIF I } \\
\text { GRUP }\end{array}$} & $\begin{array}{c}\text { Grup } \\
(\mathbf{n}=\mathbf{1 5})\end{array}$ & $\begin{array}{c}\text { Grup } \\
(\mathbf{n}=\mathbf{1 5})\end{array}$ & $\begin{array}{c}\text { Grup } \\
(\mathbf{n}=\mathbf{1 5})\end{array}$ & \\
\cline { 2 - 5 } & $\mathbf{X} \pm \mathbf{S d}$ & $\mathbf{X} \pm \mathbf{S d}$ & $\mathbf{X} \pm \mathbf{S d}$ & $\mathbf{p}$ \\
\hline Yaș (yl) & $16,63 \pm 1,36$ & $16,92 \pm 1,07$ & $17,46 \pm 1,85$ & 0,754 \\
\hline ANB $\left(^{\circ}\right)$ & $3,01 \pm 0,23$ & $3,33 \pm 0,21$ & $2,23 \pm 0,29$ & 0,388 \\
\hline Overjet $(\mathbf{m m})$ & $1,73 \pm 0,20$ & $1,86 \pm 0,13$ & $2,06 \pm 0,16$ & 0,420 \\
\hline Overbite $(\mathbf{m m})$ & $1,61 \pm 0,19$ & $1,88 \pm 0,09$ & $2,12 \pm 0,28$ & 0,840 \\
\hline \hline
\end{tabular}

Sinf I, $0>$ ANB $<4$;

hipodiverjan, $\mathrm{SNGoGn}<27$;

normodiverjan, $27>\mathrm{SNGoGN}<37$

hiperdiverjan; $\mathrm{SNGoGn}>37$;

$\mathrm{X}$, ortalama;

Sd, standart deviasyon;

$\mathrm{n}$, birey sayıs ;

$\mathrm{p}, \mathrm{t}$ testine göre önemlilik düzeyi. 


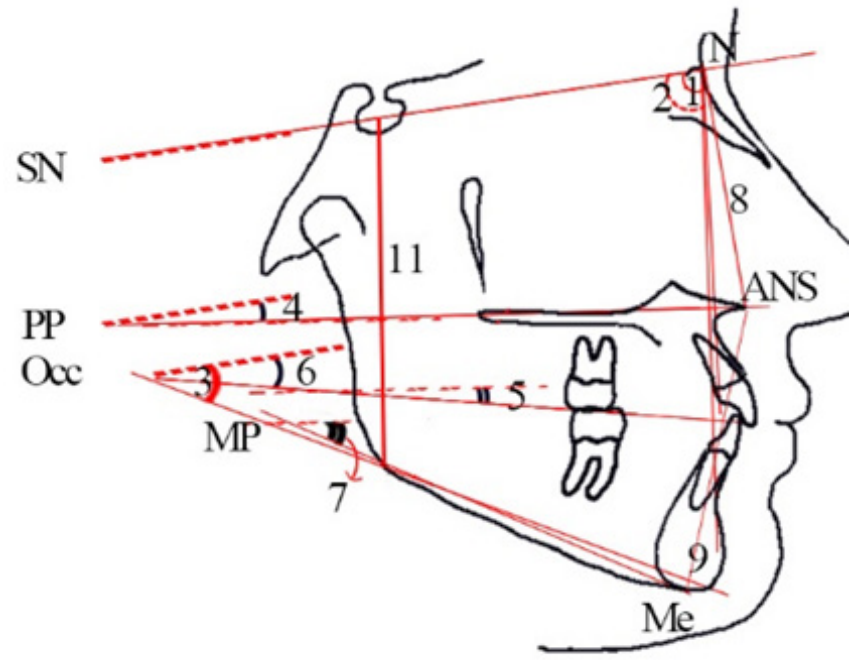

Şekil 1. İskeletsel açısal ve doğrusal ölçümler

1, SNA $\left({ }^{\circ}\right) ; 2, \mathrm{SNB}\left({ }^{\circ}\right) ; 3, \mathrm{SN}-\mathrm{GoGN}\left({ }^{\circ}\right) ; 4, \mathrm{SN} / \mathrm{PP}\left({ }^{\circ}\right) ; 5, \mathrm{Occ} / \mathrm{PP}\left({ }^{\circ}\right) ; 6, \mathrm{Occ} / \mathrm{SN}\left({ }^{\circ}\right) ; 7, \mathrm{MP} / \mathrm{PP}\left({ }^{\circ}\right) ; 8$, N-ANS (mm); 9, ANS-Me (mm); 10, N-Me (mm); 11, S-Go (mm); 12, S-Go/N-Me (mm).

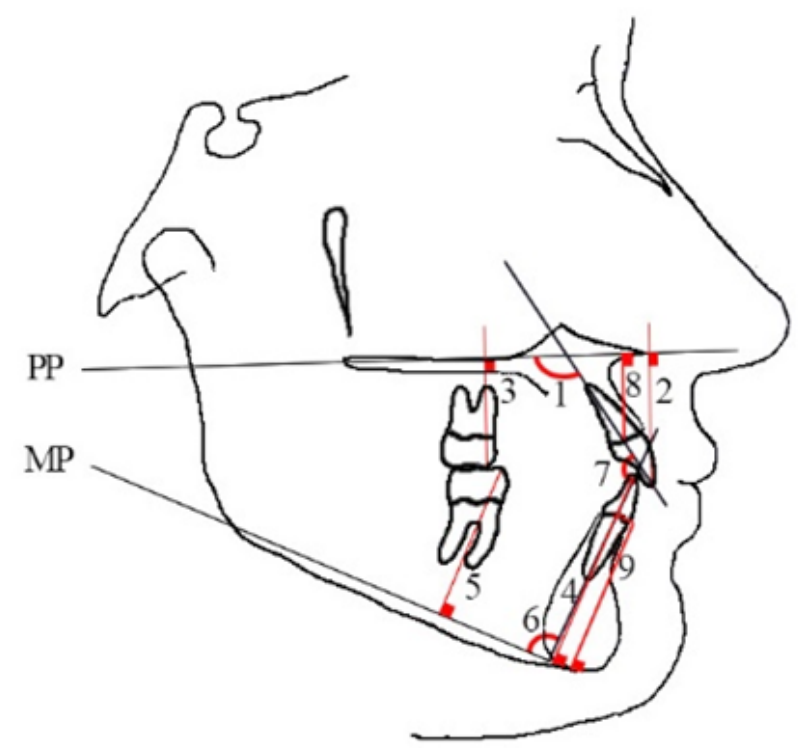

Sekil 2. Dentoalveoler ölçümler

1. U1/PP( $\left.{ }^{\circ}\right) ; 2$, U1-PP(mm); 3, U6-PP(mm); 4, L1-MP(mm); 5, L6-MP(mm); 6, IMPA $\left(^{\circ}\right) ; 7$, U1/L1 $\left.{ }^{\circ}\right), 8$, MxAAY $(\mathrm{mm})$ maksiller anterior dentoalveoler yükseklik;9, MdAAY $(\mathrm{mm})$ mandibuler anterior dentoalveoler yükseklik.

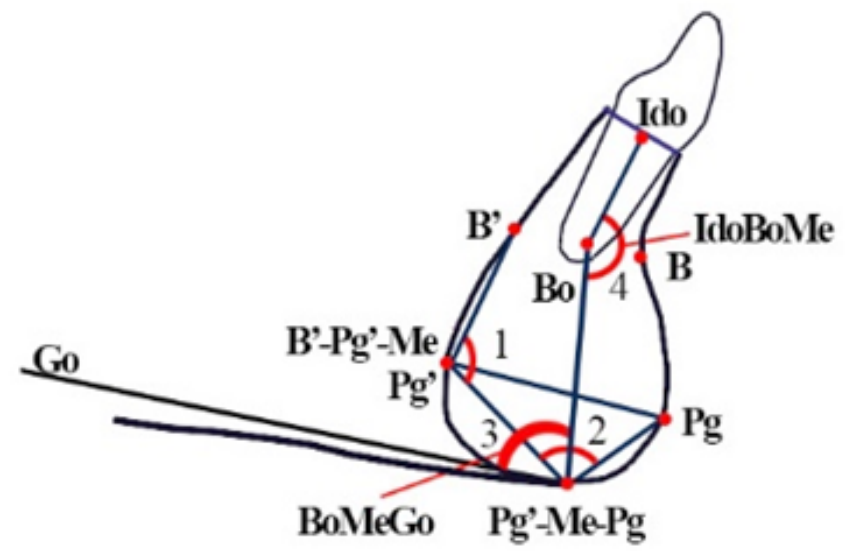

Sekil 3. Mandibuler simfizin açısal ölçümleri

1, B'-Pg'-Me' $\left(^{\circ}\right)$ Simfiz alt-arka yüzey açısı; 2, Pg'-Me-Pg $\left({ }^{\circ}\right)$ Mental açı; 3, BoMeGo $\left({ }^{\circ}\right)$ Simfiz eğimi; 4 , IdoBoMe $\left(^{\circ}\right)$ Simfiz iç eğimi.

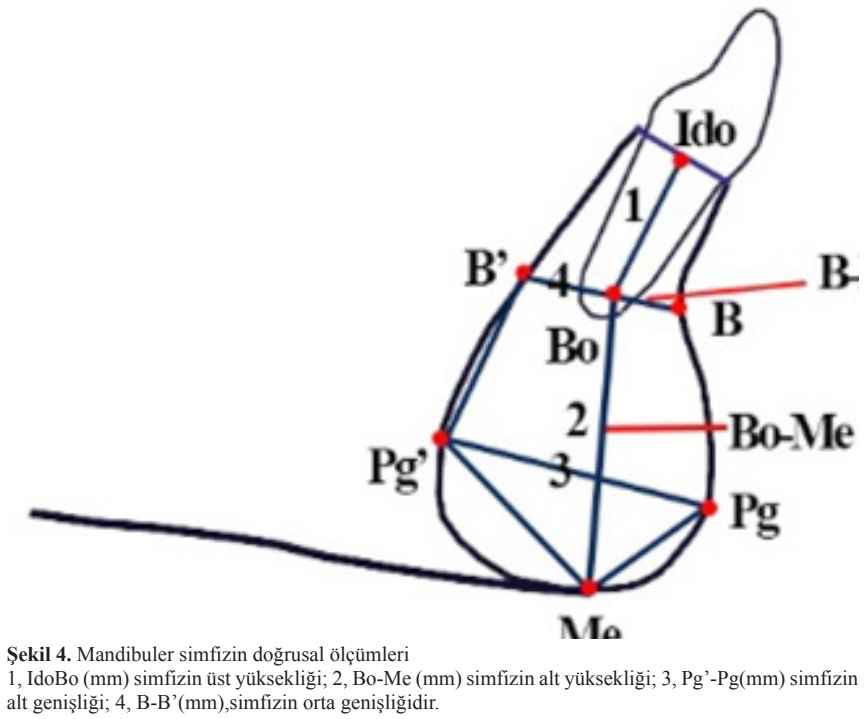

Ölçümlerin 1/3, ü 3 hafta sonra tekrarlanmış, lateral sefalometrik radyograflardan elde edilen ölçüme ilişkin tekrarlama katsayıları 1 tam değerine yaklaşık bulunmuştur $(\mathrm{r}=$ 0.999-0.971). Çalışmamızın istatistiksel analizleri Statistical Package for Social Science (SPSS Inc, Chicago, Illinois, USA) 18,0 for Windows yazılımı kullanılarak yapılmıştır. Chi-square bağımsızlık testi yapılarak, cinsiyetlerin gruplara dağılımının benzerlik gösterip göstermediği belirlenmiștir. Yaş, ANB açısı, overjet ve overbite ölçümlerinin ortalamaları arasında t testi yapılmıştır. Gruplar arası farklılık incelenirken One Way ANOVA Testi kullanılmıştır. One Way ANOVA testinde DUNCAN testi kullanılarak hangi gruplar arasında farklılığın olduğu belirlenmiştir. Çalışmada dik yön ölçümleri ile simfiz ve dentoalveolar ölçümler arasında bir ilişki olup olmadığı Pearson korelasyon katsayısı ile araştırılmıştır.

\section{Bulgular}

Sınıf I hiperdiverjan, normodiverjan ve hipodiverjan alt grupları içinde SNA ve SNB ölçüm değerleri $p<0,001$ düzeyinde istatistiksel olarak anlamlıdır. Sınıf I alt grupların karşılaştırmasında SNA ve SNB ölçüm değerinin hipodiverjan gruptan hiperdiverjan gruba doğru azaldığ1 görülmüştür. $(p<0,001)$. Sınıf I dik yön alt gruplarının karşılaştırılmasında SN/GoGn ve SN/PP ölçüm değerleri $\mathrm{p}<0,001$ düzeyinde istatistiksel olarak anlamlıdır. Dik yön azaldıkça bu açıların değerleri de azalmaktadır $(p<0,001)$. $\mathrm{Occ} / \mathrm{PP}, \mathrm{Occ} / \mathrm{SN}$ ve MP/PP ölçümleri $\mathrm{p}<0,001$ düzeyinde istatistiksel olarak anlamlı bulunmuştur. Bu ölçüm değerleri hiperdiverjan gruptan hipodiverjan gruba doğru azalmıştır. N-ANS ölçüm değerleri bakımından istatistiksel olarak anlamlı bir farklılık bulunmamışken $(p>0,05)$, ANSMe ve N-Me ölçümleri bakımından istatistiksel olarak anlamlı bir farklılık bulunmuştur $(p<0,001)$. Sınıf I dik yön alt gruplarının karşılaştırılmasında $\mathrm{S}-\mathrm{Go}$ ve $\mathrm{S}-\mathrm{Go} / \mathrm{N}$ Me (Jaraback Oranı) ölçüm değerleri bakımından istatistik olarak anlamlı bir farklılık bulunmaktadır $(\mathrm{p}<0,001)$. Ölçüm değerleri hiperdiverjan gruptan hipodiverjan gruba doğru artış göstermiştir ( $\mathrm{p}<0,001)$. (Tablo 2) 
Tablo 2. Sinif I gruba ait hiperdiverjan, normodiverjan ve hipodiverjan alt gruplarındaki iskeletsel parametrelerin standart sapmaları, ortalamaları ve istatistik değerlendirilmesi.

\begin{tabular}{|c|c|c|c|c|c|}
\hline \multirow{4}{*}{$\begin{array}{l}\text { İskeletsel } \\
\text { Ölç̣ümler }\end{array}$} & \multicolumn{3}{|c|}{ SINIF I } & & \\
\hline & $\begin{array}{c}\text { Hiperdiverjan } \\
\mathrm{n}=15\end{array}$ & $\begin{array}{c}\text { Normodiverjan } \\
n=5\end{array}$ & $\begin{array}{c}\text { Hipodiverjan } \\
\quad \mathrm{n}=15\end{array}$ & & \\
\hline & 1 & 2 & 3 & & \\
\hline & $\mathrm{X} \pm \mathrm{Sd}$ & $\mathrm{X} \pm \mathrm{Sd}$ & $\mathrm{X} \pm \mathrm{Sd}$ & p & $\begin{array}{lll}1-2 & 1-3 & 2-3 \\
\end{array}$ \\
\hline SNA $\left(^{\circ}\right)$ & $77,01 \pm 0,55$ & $81,60 \pm 0,52$ & $83,88 \pm 0,81$ & 0,000 & *******; \\
\hline$\overline{\mathrm{SNB}}\left(^{\circ}\right)$ & $74,00 \pm 0,59$ & $78,26 \pm 0,49$ & $81,65 \pm 0,68$ & 0,000 & *********; \\
\hline$\overline{\text { SN-GoGN }\left({ }^{\circ}\right)}$ & $43,96 \pm 0,72$ & $32,66 \pm 0,52$ & $24,57 \pm 0,45$ & 0,000 & $* * * * * * *$ \\
\hline$\overline{\mathrm{SN}} / \mathrm{PP}\left({ }^{\circ}\right)$ & $11,24 \pm 0,71$ & $9,46 \pm 0,29$ & $6,77 \pm 0,78$ & 0,000 & 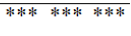 \\
\hline$\overline{\mathrm{Occ} / \mathrm{PP}\left({ }^{\circ}\right)}$ & $14,20 \pm 1,14$ & $7,65 \pm 0,94$ & $4,41 \pm 0,88$ & 0,000 & 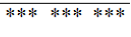 \\
\hline$\overline{\mathrm{Occ} / \mathrm{SN}\left({ }^{\circ}\right)}$ & $24.22 \pm 1,29$ & $18,80 \pm 0,80$ & $11,56 \pm 0,80$ & 0,000 & $* * * * * * * * *$ \\
\hline$\overline{\mathrm{MP} / \mathrm{PP}}\left({ }^{\circ}\right)$ & $33,60 \pm 0,85$ & $22,80 \pm 0,71$ & $18,15 \pm 0,70$ & 0,000 & ********** \\
\hline N-ANS (mm) & $49,66 \pm 1,05$ & $49,73 \pm 1,36$ & $49,18 \pm 1,19$ & 0,940 & NS NS NS \\
\hline ANS-Me (mm) & $67,26 \pm 0,52$ & $62,20 \pm 1,01$ & $58,34 \pm 1,41$ & 0,000 & 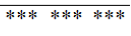 \\
\hline N-Me (mm) & $117,60 \pm 1,03$ & $112,00 \pm 0,95$ & $106,75 \pm 2,20$ & 0,000 & $* * * * * * * * *$ \\
\hline S-Go (mm) & $69,53 \pm 1,10$ & $74,20 \pm 0,75$ & $78,18 \pm 1,58$ & 0,000 & **** \\
\hline S-Go/N-Me (mm) & $58,26 \pm 0,75$ & $64,30 \pm 0,52$ & $73,33 \pm 0,77$ & 0,000 & ***; \\
\hline
\end{tabular}

Hipodiverjan, SNGoGn $<27$;

normodiverjan, 27>SNGoGN $<37$;

hiperdiverjan, $\mathrm{SNGoGn}>37$;

$\mathrm{X}$, ortalama;

$\mathrm{Sd}$, standart deviasyon

$\mathrm{n}$, birey sayisı;

$* * *, \mathrm{p}<0,001$

**, $\mathrm{p}<0,01$;

*, $\mathrm{p}<0,05 ; \mathrm{NS}$, önemsiz;

$\mathrm{p}$, ANOVA testine göre önemlilik düzeyi.

Sınıf I dik yön alt gruplarının karşılaştırılmasında U1/PP ölçümü bakımından istatistiksel olarak anlamlı bir farklılık bulunmuştur $(p<0,05)$. Hiperdiverjan ve normodiverjan, hiperdiverjan ve hipodiverjan alt grupları arasında istatistiksel fark vardır $(p<0,01)$. U1/L1 ölçüm değerleri bakımından istatistiksel olarak anlamlı bir farklılık yoktur $(p>0,05)$. IMPA ölçüm değerleri bakımından istatistiksel olarak anlamlı bir farklılık bulunmaktadır $(\mathrm{p}<0,001)$. Bu açı dik yön azaldıkça artmaktadır $(\mathrm{p}<0,01)$. U1 $\perp_{\mathrm{PP}}$ ölçüm değerleri bakımından istatistik olarak anlamlı bir farklılık bulunmaktadır $(p<0,001)$. Hiperdiverjan gruptan hipodiverjan gruba doğru gittikçe azaldığı görülmüştür.U6 ${ }^{\perp} P P$ ölçümü bakımından istatistiksel olarak anlamlı bir farklılık bulunmuştur $(p<0,05)$. Hiperdiverjan-normodiverjan ve Hiperdiverjan-hipodiverjan grupları arasındaki fark istatistiksel olarak anlamlıdır $(\mathrm{p}<0.05) . \quad \mathrm{L} 1 \perp_{\mathrm{MP}}$ ölçümü bakımından istatistiksel olarak anlamlı bir farklılık bulunmuştur $(\mathrm{p}<0,01)$. Normodiverjan ve hipodiverjan grupları arasındaki fark, istatistiksel olarak anlamlı değil iken ( $\mathrm{p}>0,05)$, hiperdiverjan ile normodiverjan ve hiperdiverjan ile hipodiverjan grupları arasındaki farklılığın $\mathrm{p}<0,05$ düzeyinde istatistiksel olarak anlamlı olduğu saptanmıştır. L1 $\perp_{\mathrm{MP}}$ ölçüm değerinin hiperdiverjan grupta bulunan hastalarda normodiverjan ve hipodiverjan grupta bulunan hastalardan daha fazla olduğu görülmüştür. Maksiller anterior dentoalveoler yükseklik (MxAAY) ve mandibuler anterior dentoalveoler yükseklik (MdAAY) ölçümü bakımından istatistiksel olarak anlamlı bir farklılık bulunmuştur ( $\mathrm{p}<0,01)$. (Tablo 3 )
Tablo 3. Sınıf I gruba ait hiperdiverjan, normodiverjan ve hipodiverjan alt gruplarındaki dentoalveoler parametrelerin standart sapmaları, ortalamalar ve istatistik değerlendirilmesi.

\begin{tabular}{|c|c|c|c|c|c|c|c|}
\hline \multirow{4}{*}{$\begin{array}{c}\text { Dentoalveoler } \\
\text { Ölçüimler }\end{array}$} & \multicolumn{3}{|c|}{ SINIF I } & & & & \\
\hline & $\begin{array}{c}\text { Hiperdiverjan } \\
n=15\end{array}$ & $\begin{array}{c}\text { Normodiverjan } \\
n=15\end{array}$ & $\begin{array}{l}\text { Hipodiverjan } \\
\qquad n=15\end{array}$ & & & & \\
\hline & 1 & 2 & 3 & & & & \\
\hline & $\mathrm{X} \pm \mathrm{Sd}$ & $\mathrm{X} \pm \mathrm{Sd}$ & $\mathbf{X} \pm \mathbf{S} \mathbf{d}$ & p & $1-2$ & $1-3$ & $2-3$ \\
\hline$\overline{\mathrm{U} 1 / \mathrm{PP}}\left(^{\circ}\right)$ & $107,13 \pm 0,93$ & $111,73 \pm 0,56$ & $111,46 \pm 0,81$ & 0,010 & $* *$ & *** & NS \\
\hline$\overline{\left.\mathrm{U} 1 / \mathrm{L} 1{ }^{\circ}\right)}$ & $132,33 \pm 1,83$ & $129,80 \pm 0,91$ & $132,87 \pm 1,67$ & 0,330 & NS & NS & NS \\
\hline IMPA ( $\left.{ }^{\circ}\right)$ & $84,57 \pm 1,14$ & $92,86 \pm 0,81$ & $97,25 \pm 1,18$ & 0,000 & *wak & w水水 & *** \\
\hline$\overline{\mathrm{U} 1} \perp^{\perp} \mathbf{P P}(\mathrm{mm})$ & $32,13 \pm 0,93$ & $29,33 \pm 0,55$ & $27,00 \pm 0,71$ & 0,000 & $* *$ & *** & NS \\
\hline$\overline{\mathrm{U}} \mathbf{6}^{\perp} \mathrm{PP}(\mathrm{mm})$ & $26,20 \pm 0,69$ & $24,93 \pm 0,52$ & $23,18 \pm 0,70$ & 0,049 & $*$ & $*$ & NS \\
\hline$\overline{\mathrm{L}} \mathbf{1}^{\perp} \mathrm{MP}$ (mm) & $42,73 \pm 0,93$ & $40,06 \pm 0,45$ & $39,12 \pm 0,81$ & 0,007 & $*$ & k* & NS \\
\hline$\overline{\mathrm{L}}{ }^{\perp} \perp_{\mathrm{MP}}(\mathrm{mm})$ & $32,86 \pm 0,75$ & $33,53 \pm 0,54$ & $34,06 \pm 6,22$ & 0,765 & NS & NS & NS \\
\hline$\overline{\mathrm{MxAAY}}(\mathbf{m m})$ & $24,13 \pm 1,24$ & $20,60 \pm 0,50$ & $18,87 \pm 1,12$ & 0,002 & $* *$ & **** & $*$ \\
\hline$\overline{\text { MdAAY (mm) }}$ & $34,93 \pm 1,36$ & $31,60 \pm 0,50$ & $28,87 \pm 0,79$ & 0,000 & $* *$ & **ak & $* * *$ \\
\hline
\end{tabular}

Hipodiverjan, SNGoGn $<27$;

normodiverjan, $27>\mathrm{SNGoGN}<37$;

hiperdiverjan, $\mathrm{SNGoGn}>37$;

$\mathrm{X}$, ortalama;

Sd, standart deviasyon;

n, birey sayis1;

$* * *, \mathrm{p}<0,001$

$* *, \mathrm{p}<0,01$

$*, \mathrm{p}<0,05$;

NS, önemsiz;

p, ANOVA testine göre önemlilik düzeyi.

Tablo 4. Sinıf I gruba ait hiperdiverjan, normodiverjan ve hipodiverjan alt gruplarındaki simfizyal parametrelerin standart sapmaları, ortalamaları ve istatistik değerlendirilmesi.

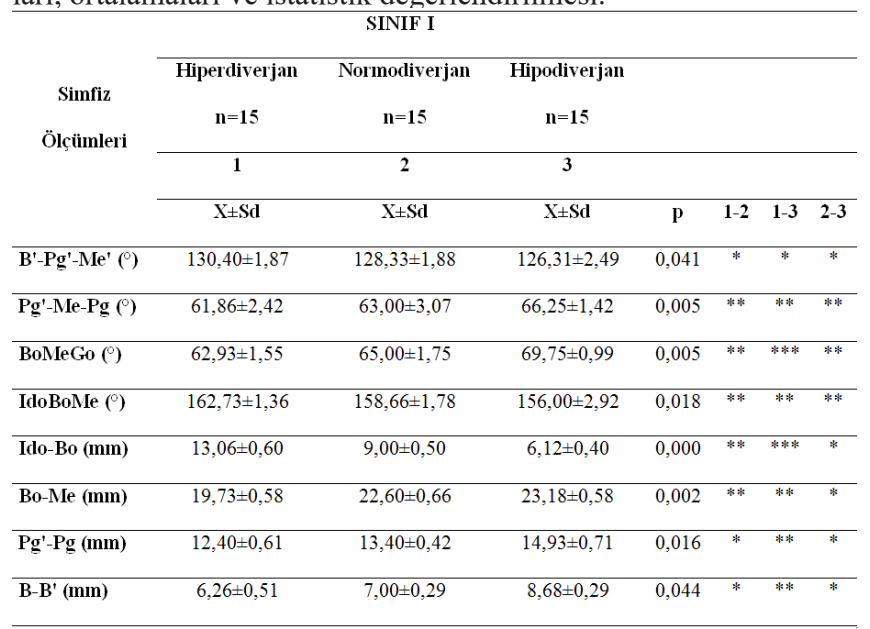

Hipodiverjan, SNGoGn $<27$

normodiverjan, 27>SNGoGN $<37$;

hiperdiverjan, $\mathrm{SNGoGn}>37$;

$\mathrm{X}$, ortalama;

Sd, standart deviasyon;

n, birey sayısı;

$* * *, \mathrm{p}<0,001$

$* *, \mathrm{p}<0,01$

*, $\mathrm{p}<0,05$;

NS, önemsiz;

p, ANOVA testine göre önemlilik düzeyi. 
Sınıf I dik yön alt gruplarının karşılaştırılmasında simfizin alt arka yüzey açısı (B'-Pg'-Me) bakımından istatistiksel olarak anlamlı bir farklılık bulunmuştur $(\mathrm{p}<0,05)$. B'-Pg'-Me ölçüm değeri hiperdiverjan gruptan hipodiverjan gruba doğru azalmıştır. Simfiz mental açısı (Pg'-Me-Pg) ölçüm değerleri bakımından istatistik olarak anlamlı bir farklılık bulunmaktadır $(\mathrm{p}<0,01)$. Pg'-Me-Pg ölçüm değerinin hiperdiverjan gruptan hipodiverjan gruba doğru artış gösterdiği görülmüştür. Simfiz eğimi (BoMeGo) bakımından istatistik olarak anlamlı bir farklılık bulunmaktadır $(\mathrm{p}<0,01)$. Hipodiverjan gruptaki bireylerin BoMeGo ölçüm değerleri diğer gruplara göre daha yüksektir. Bunu normodiverjan grup izlemektedir. Simfiz iç eğimi (IdoBoMe) bakımından istatistik olarak anlamlı bir farklılık bulunmaktadır $(\mathrm{p}<0,05)$. Hiperdiverjan gruptaki hastaların IdoBoMe ölçüm değerleridiğer gruplara göre daha yüksektir. Üst simfiz yüksekliği (Ido-Bo) bakımından istatistik olarak anlamlı bir farklılık bulunmaktadır $(p<0,001)$. Hiperdiverjan gruptaki hastaların Ido-Bo ölçüm değerleri diğer gruplara göre daha yüksektir. Alt simfiz yüksekliği (Bo-Me) bakımından istatistiksel olarak anlamlı bir farklılık bulunmuştur $(\mathrm{p}<0,01)$. (Tablo 4$)$

\section{Tartışma}

Dentoalveoler kompanzasyon, sagittal ve vertikal yönde anomalinin oluşuma yol açan iskeletsel uyumsuzlukların telafi edilmesinde önemli rol oynar. Bu çalışmada yer alan her bir Sinıf I dik yön grubunun ANB, overjet, overbite ortalama değerlerinin normal sinırlar içinde olduğu ve çalışmada incelenmek istenen iskeletsel anomalilerin özelliklerini yansıttığı görülmektedir. (Tablo 1) Gruplarda yer alan bireylerin vertikal anomaliyi dentoalveoler düzeyde kompanze ederek "normal overjet-overbite" değerlerine ulaşması (11) ve ortalamaların normal kabul edilen aralıkta olması aslında bu çalışmada yer alan grupların çalışma için uygun olan ve iskeletsel anomaliye sahip gerçek dentoalveoler kompanzasyonlu bireyler olduğunu göstermektedir.

$\mathrm{Bu}$ çalışma sonuçlarına göre Sınıf I bireylerde büyüme paterninin vertikale doğru kayması ve dik yönün artışı ile maksillanın (SNA) ve mandibulanın kafa kaidesine göre konumunun (SNB) ön-arka yönde daha geride konumlandığı (retrüziv maksilla ve mandibula) belirlenmiştir. $\mathrm{Bu}$ sonuç literatür ile uyumludur(12,13). Bishara ve Jakobsen, yüzün dik yön boyutları artmış bireylerde maksilla ve mandibulanın normale göre daha retrüziv konumda bulunduğunu ancak her iki çenenin senkronize olduğunu vurgulamışlardır(14). Bu sonuçlara paralel olarak, çalışmamızda da SNA ve SNB açıları birbirleriyle uyumlu olarak artma veya azalma göstermiştir. Çalışma sonuçlarına göre palatal düzlemin kafa kaidesi ile yaptığı palatal açı (SN/PP) Sınıf I bireylerde dik yöne eşlik ederek artmıștır. Dik yön boyutları artmıș olan bireylerde SN/ PP açısındaki artışın ön açık kapanış oluşumunu önleyen bir adaptasyon olduğunu belirtilmiştir $(2,15)$. Oklüzal düzlemin kafa kaidesi ile yaptığı okluzal açı (Occ/SN) ve palatal planın oklüzal düzlem ile yaptığı açı (Occ/PP) açı Sınıf I sagittal yön anomalisine sahip her bir grupta dik yöndeki değişikliğe adapte olarak dentoalveoler kompanzasyona direkt katılmıştır. $\mathrm{Bu}$ sonuç literatür ile uyumludur (4.11). Palatal plan ile mandibuler plan arasındaki açı (PP/MP)dik yön artışına eşlik etmiştir. Hiperdiverjan bireylerde PP/MP açısının artışının maksillanın anterior rotasyonundan kaynaklandığını belirtildiği (19-21) gibi, bu açının artışından mandibulanın posterior rotasyonunun sorumlu olduğu da ifade edilmiştir (7). Üst ön yüz yüksekliği (N-ANS), çalışmamızda tüm Sınıf I alt grupları arasında istatistiksel olarak benzerdir. Bu sonuç literatür ile uyumludur(16). Bu sonuca zit olarak hipodiverjan bireylerde üst ön yüz yüksekliğinin arttığını bildiren çalışmalar da vardır (17-19). Bu zıt sonuçların sebebi, çalışma grubuna dâhil edilen bireylerin seçimindeki farklılık olabilir. Alt ön yüz yüksekliği (ANS-Me) çalışmamızda Sınıf I, tüm alt grupları arasında hiperdiverjan gruptan hipodiverjan gruba doğru gidildikçe azalmıştır. Bu sonuç literatür ile uyumludur $(12,13,19)$. Kuitert et al. özellikle uzun yüzlü bireylerde alt yüz yüksekliğinin overbite ile yakından ilişkili olduğunu belirterek, bayanlarda alt yüz yüksekliğinin $72 \mathrm{~mm}$ 'den fazla, erkeklerde ise $76 \mathrm{~mm}$ 'den fazla olduğu bireylerde maksiller ve mandibular frontal alveolar ve bazal adaptif değişikliklerin açık kapanış oluşmasını engelleyemediğini bildirmiştir. $\mathrm{Bu}$ çalışmada ölçülen en yüksek ANS-Me boyutu 67 mm'dir (3). S-Go/N-Me oranı, Sinıf I, grupta hipodiverjan gruptan hiperdiverjan gruba doğru gidildikçe azalmaktadır. Sonuç literatür ile uyumludur $(12,20)$. Üst keserler palatal plana göre (U1/PP) Sınıf I hiperdiverjan gruptaki bireylerde daha retrüzivdir (21). Alt keserler ise mandibuler plana göre (IMPA) Sınıf I hipodiverjan bireylerden hiperdiverjan bireylere doğru gidildikçe daha retrüziv konumlanmıştır. Ek olarak, dik yön boyutlarının artışı ile üst ve alt keserlerin kendi kaideleri ile arasındaki açının güçlü negatif korelasyon gösterdiği tespit edilmiştir (Tablo 5). Bu sonuç, Sınıf I bireylerde yüzün dik yön boyutlarını belirleyen açısal ölçümlerdeki ve alt yüz yüksekliğindeki artışla birlikte alt ve üst keserlerin kendi kaidelerine göre retrüziv konumlandıklarını, arka yüz yüksekliklerindeki artışla birlikte ise daha protrüziv konumlandıklarını göstermektedir.

Bulgularımıza göre, farklı dik yön boyutlarına sahip Sınıf I bireylerde üst ve alt keser konumlarındaki değişikliğe rağmen keserler arası açının (U1/L1) benzer olması dikkat çekicidir. Literatürde maksiller ve mandibuler dentoalveoler yüksekliklerin keser inklinasyonlarından etkilendiği bildirilmektedir (22). Kısa yüzlü bireylerde üst keser inklinasyonundaki adaptasyonların üst keserlerin alveolar ve bazal yüksekliklerinin efektif vertikal boyutunda azalmaya izin vereceğini, böylece derin kapanışın oluşmasının engelleneceği bildirilmiştir (3).

Sinıf I grubun hiperdiverjan, hipodiverjan ve normodiverjan alt grupları dentoalveoler yükseklikler bakımından değerlendirildiğinde, üst keserlerin palatal düzleme olan uzaklığının $\left(\mathrm{U} 1 \perp_{\mathrm{PP}}\right)$ ve anterior maksiller alveoler yüksekliğin (MxAAY) hiperdiverjan gruptan hipodiverjan gruba doğru gidildikçe azaldığı görülmüştür. Aynı şekilde, alt keserlerin de mandibuler düzleme olan uzaklığ $\left(\mathrm{L} 1 \perp_{\mathrm{MP}}\right)$ ve anterior mandibuler alveoler yükseklik (MdAAY) hiperdiverjan gruptan hipodiverjan gruba doğru gidildikçe azalmaktadır. Ek olarak, dik yön ölçümleri ile $\mathrm{U} 1 \perp_{\mathrm{PP}}, \mathrm{MxAAY}, \mathrm{L} 1 \perp_{\mathrm{MP}}$, ölçümleri arasında güçlü pozitif korelasyon görülmüştür 
Tablo 5. Sınıf I bireylerde dik yön boyut ölçümleri ve dentoalveoler ölçümler arasındaki korelasyon tablosu.

\begin{tabular}{|c|c|c|c|c|c|c|c|c|c|c|}
\hline Ölçümler & $\begin{array}{c}\mathrm{U1} / \mathrm{PP} \\
\left({ }^{\circ}\right)\end{array}$ & $\begin{array}{c}\text { IMPA } \\
\left({ }^{\circ}\right)\end{array}$ & $\begin{array}{c}\mathrm{U} 1 \perp \mathrm{PP} \\
(\mathrm{mm})\end{array}$ & $\begin{array}{c}\mathrm{U} 6 \perp \mathrm{PP} \\
(\mathrm{mm})\end{array}$ & $\begin{array}{c}\mathrm{L} 1 \perp_{\mathrm{MP}} \\
(\mathrm{mm})\end{array}$ & $\begin{array}{c}\mathrm{L6}{ }^{\perp \mathrm{MP}} \\
(\mathrm{mm})\end{array}$ & $\begin{array}{l}\text { MxAAY } \\
\text { (mm) }\end{array}$ & $\begin{array}{l}\text { MdAAY } \\
\text { (mm) }\end{array}$ & $\begin{array}{c}\mathrm{Occ} / \mathrm{PP} \\
\left({ }^{\circ}\right)\end{array}$ & $\begin{array}{c}\mathrm{Occ} / \mathrm{SN} \\
\left({ }^{\circ}\right)\end{array}$ \\
\hline SnGoGn $\left(^{\circ}\right)$ & $-0,390^{* *}$ & $-0,828^{*} *$ & $0,596^{* *}$ & $0,362^{* *}$ & $0,487^{* *}$ & $-0,055$ & $0,454^{* *}$ & $0,559^{* *}$ & $0,935^{* *}$ & $0,771^{* *}$ \\
\hline$\overline{\operatorname{ArGoMe}\left({ }^{\circ}\right)}$ & $-0,211$ & $-0,731^{* *}$ & $0,414^{* *}$ & 0,173 & $0,321^{*}$ & $-0,005$ & $0,388^{* *}$ & $0,534^{* *}$ & $0,715^{* * *}$ & $0,501^{* *}$ \\
\hline ANS-Me (mm) & $-0,156$ & $-0,466^{* *}$ & $0,664 * *$ & $0,527^{* *}$ & $0,608^{* *}$ & 0,136 & $0,577^{* *}$ & $0,583^{* *}$ & $0,661 * *$ & $0,515^{* *}$ \\
\hline S-Go (mm) & $0,313^{*}$ & $0,491^{* *}$ & 0,131 & $-0,415^{* *}$ & $-0,321^{*}$ & 0,179 & 0,007 & 0,086 & 0,036 & $-0,096$ \\
\hline S-Go/ N-Me(mm) & 0,313 & $0,823 * *$ & $-0,545^{* *}$ & $-0,278^{*}$ & $-0,442, * *$ & 0,04 & $-0,452^{* *}$ & $-0,534^{* *}$ & $-0,534^{* *}$ & $-0,498^{* *}$ \\
\hline
\end{tabular}

(Tablo 5). Bu sonuç, Sınıf I bireylerde yüzün dik yön açıları ve alt yüz yüksekliğini artışı ile alt ve üst keserlerin ekstrüze olduğunu maksiller ve mandibuler anterior alveoler bazal kemik yüksekliğinin arttığını göstermektedir. Bulgularımız literatür ile uyumludur (12). Kucera ve ark.(6), dik yön boyutları artmış olan bireylerde vertikal yönde dentoalveoler kompanzasyonun alt çenede daha fazla olmak üzere hem üst hem de alt anterior dentoalveoler yüksekliklerinin artışı ile gerçekleştiğini bildirmişlerdir. Kuitert ve ark. (3)'da bulgularımızla uyumlu olarak, mandibuler anterior dentoalveoler yüksekliğin vertikal gelişim ile bağlantılı olarak arttığını ve kompanzasyon mekanizmasına katkıda bulunduğunu belirtmișlerdir. Ayrıca hiperdiverjan bireylerde açık kapanışın engellenmesine yönelik alt keserlerin alveolar ve bazal yüksekliklerinin adaptif değişiminin keserlerin kök uzunlukları, apikal inervasyon, kan akışındaki artış ve mandibulanın kortikal kalınlığı gibi bir takım faktörler tarafından sınırlandırılabileceğini bildirmişlerdir. Buna karşılık hipodiverjan bireylerde anterior alveolar ve bazal yüksekliklerin azalmasına yönelik böylesine aşırı bir kompanzasyona ihtiyaç olmadığı görüşünü savunmuşlardır. Anwar (5), çalışmasında SN-MP açısının her 1 derece artışında, alt keser alveol boyutunda $0,22 \mathrm{~mm}$ yükseklik artışı olduğunu bildirmiştir. Fields ve ark.(23), hiperdiverjan bireylerde açık kapanış oluşumunun engellenmesinde alt anterior dentoalveoler yükseklik artışını sorumlu tutmakla birlikte, üst anterior dentoalveoler yüksekliğin biraz artmasına rağmen fazla bir değişiklik göstermediğini bildirmişlerdir. Açıkbaş (24) ise anterior dentoalveoler bölgede açık kapanışın eliminasyonunda üst anterior dentoalveoler bölgedeki yükseklik artışının alt anterior dentoalveoler bölgeye kıyasla daha etkili olduğunu bildirmişlerdir. Bulgularımızın aksine, hipodiverjan hastalarda alt keser dişlerin dentoalveoler yüksekliğinin arttığını belirten araştırıcılar da vardır (19). Bunun nedeni, araştırmacıların çalışmalarında derin kapanış ilişkisi görülen vakaları dahil etmeleri olabilir.

Sınıf I bireylerde maksiller molarların palatal düzleme olan uzaklığ1 $\left(\mathrm{U} 6 \perp^{\perp} \mathrm{PP}\right)$, hiperdiverjan grupta en fazladır. Ayrıca, alt anterior yüz yüksekliğindeki artış ile maksiller molarların palatal düzleme olan uzaklığındaki artış güçlü düzeyde korelasyon göstermiştir (Tablo 5). Buna karşıllk posterior yüz yükseklikleri ile U6 ${ }^{\perp}$ PP ölçümü arasında orta düzeyde negatif korelasyon görülmüştür (Tablo 5). Bu sonuç, ideal overjet-overbite ilişkisine sahip Sınıf I bireylerde alt ön yüz yüksekliğindeki artış ile birlikte, maksiller molarların palatal düzleme olan uzaklığının da arttığını göstermektedir. $\mathrm{Bu}$ bireylerde arka yüz yükseklikleri maksiller molarların palatal düzleme olan uzaklığı orta düzeyli negatif korelasyon göstermektedir (Tablo 5).

Mandibuler molarların mandibuler düzleme olan uzaklığı ise (L6 ${ }^{\perp}$ MP) Sinıf I alt grupların tümünde benzerdir. Bu sonuç, farklı dik yön boyutlarına sahip bireylerde vertikal yönde dentoalveoler kompanzasyonun sağlanmasında mandibuler posterior dentoalveoler yüksekliğin korunduğunu göstermektedir. Bulgularımız literatür ile uyumludur (6). Sonuçlarımızdan farklı olarak, yüzün dik yön boyutlarının artmış olduğu vakalar ile ilgili yapılan çalışmaların bazılarında alt posterior dentoalveoler bölge yüksekliğinin arttığ 1 bildirilirken $(19,23)$, hipodiverjan hastalarda, alt molar dişlerin alveoler kemik yüksekliğinin azaldığı belirtilmiştir (25).

Simfiz alt arka yüzey açısı (B'Pg'Me) ve simfiz iç eğimi (IdoBoMe) Sinif I grupta hiperdiverjan bireylerden hipodiverjan bireylere doğru azalmıştır. Dik yön boyutlarının artışı ile simfiz arka yüzey açısındaki (B'Pg'Me) ve simfiz iç eğimaçısındaki(IdoBoMe)azalmanın güçlüpozitifkorelasyon gösterdiği tespit edilmiştir. Posterior yüz yüksekliklerinin ise simfiz morfolojisini belirleyen açısal ölçümler ile istatistiksel olarak anlamlı korelasyon göstermediği sonucuna varılmıştır (Tablo 6). Buna karşılık, simfiz mental açısı (Pg’MePg) ve simfizin eğimini gösteren BoMeGo açısı Sınıf I hiperdiverjan bireylerden hipodiverjan bireylere doğru gidildikçe artmıştır. Dik yön boyutlarının artışı ile simfiz mental açısının $\left(\mathrm{Pg}{ }^{’} \mathrm{MePg}\right)$ ve simfizin eğimini gösteren BoMeGo açısının 
Tablo 6. Sınıf I bireylerde dik yön boyut ölçümleri ve simfizyal ölçümler arasındaki korelasyon tablosu.

\begin{tabular}{|c|c|c|c|c|c|c|c|c|}
\hline Ölçümler & $\mathrm{B}^{\prime}-\mathrm{Pg}^{\prime}-\mathrm{Me}\left({ }^{\circ}\right)$ & $\mathrm{Pg}^{\prime}-\mathrm{Me}-\mathrm{Pg}\left({ }^{\circ}\right)$ & BoMeGo $\left.{ }^{\circ}\right)$ & IdoBoMe $\left.{ }^{\circ}\right)$ & Ido-Bo (mm) & Bo-Me (mm) & Pg-Pg' (mm) & B-B' (mm) \\
\hline SnGoGn $\left(^{\circ}\right)$ & $0391 * *$ & $-0,450 * *$ & $-0,368 * *$ & $0,278^{*}$ & $0,468 * *$ & $-0,332^{* * *}$ & $-0,383^{* *}$ & $-0,276^{*}$ \\
\hline ArGoMe $\left(^{\circ}\right)$ & $0,257^{*}$ & $-0,253^{*}$ & $-0,421^{* *}$ & $0,276^{*}$ & $0,398 * *$ & $-0,373^{* *}$ & $-0,383^{* *}$ & $-0,276^{*}$ \\
\hline ANS-Me (mm) & $0,661 * *$ & $-0,645^{* *}$ & $-0,607^{* *}$ & $0,555^{* *}$ & $-0,251^{*}$ & $-0,226^{*}$ & $-0,319^{*}$ & $-0,279^{*}$ \\
\hline S-Go (mm) & $-0,071$ & 0,115 & 0,127 & $-0,102$ & $-0,154$ & 0,012 & 0,019 & 0,131 \\
\hline S-Go/N-Me(mm) & $-0,248^{*}$ & $0,681^{* *}$ & $0,342 * *$ & $-0,285^{*}$ & $-0,297^{*}$ & $0,490 * *$ & $0,681^{* *}$ & $0,697^{* *}$ \\
\hline
\end{tabular}

negatif korelasyon gösterdiği görülmüştür (Tablo 6). Bu sonuç, Sınıf I hiperdiverjan bireylerde ideal overjet-overbite ilișkisinin sağlanabilmesi için, simfiz arka yüzeyinin daha düz ve sı̆̆ bir görünüm kazandığını göstermiștir. Sınıf I hipodiverjan bireylerde ise, simfiz arka yüzeyi mandibuler kaide ile yaptığı açının artmış olmasından dolayı daha eğimlidir. Sınıf I hiperdiverjan bireylerde simfizin sagittal kesitinde alt yapısının daha geniş ve kıvrımlı morfolojiye sahip olduğu görülmüştür. Bu sonuçlar doğrultusunda, Sınıf I bireylerde dik yön boyutlarını ilgilendiren açısal ölçümlerdeki ve alt yüz yüksekliğindeki artış, simfizin arka yüzeyinin daha sı̆̆ ve iç eğiminin kıvrımsız olması ile ilişkilendirilmiştir. Sonuçlarımız literatür ile uyumludur $(26,27)$ Buna karşılık, Aki ve ark.(28), hipodiverjan bireylerde simfiz eğimi açısının daha dar olduğunu bildirmişlerdir. Bu uyumsuzluğun nedeni, simfiz eğimi açısının belirlenmesinde farklı referans noktaları kullanmaları olabilir.

Sinıf I grubun hiperdiverjan, hipodiverjan ve normodiverjan alt grupları simfizin milimetrik uzunluk ölçümleri bakımından değerlendirildiğinde, üst simfiz yüksekliğinin (Ido-Bo) ve mandibulanın anterior bazal kemik yüksekliğinin (MdAAY), hiperdiverjan bireylerden hipodiverjan bireylere doğru gidildikçe azaldığı görülmüştür. Alt simfiz yüksekliği (Bo-Me), ise Sinıf I hiperdiverjan bireylerden hipodiverjan bireylere doğru gidildikçe artmıştır. Simfizin total uzunluğu ise hiperdiverjan bireylerde artmışken, hipodiverjan bireylerde azalmıştır. Ayrıca, dik yön boyutlarındaki artış, üst simfiz yüksekliğindeki artış ile ve alt simfiz yüksekliğindeki azalma ilezayıf düzeyde korelasyon göstermiştir. (Tablo 6). Posterior yüz yüksekliklerinin ise simfiz yüksekliği ile istatistiksel olarak anlamlı korelasyon göstermediği sonucuna varılmıştır (Tablo 6). Bu sonuç, Sınıf I hiperdiverjan bireylerde ön açık kapanış oluşumunun engellenmesinde, simfizin üst yüksekliğindeki artışın etkin rol oynadığını göstermektedir. Sınıf I hiperdiverjan bireylerde üst simfiz yüksekliğindeki ve total simfiz uzunluğundaki artışa rağmen alt simfiz yüksekliğindeki azalma, bu bireylerde kıvrımsız simfiz morfolojisi ile birlikte B noktasının aşağı taşındığını düşündürmektedir. Literatürde bulgularımızı destekleyen çalışmalar mevcuttur $(2,8)$. Sınıf
I grubun hiperdiverjan, hipodiverjan ve normodiverjan alt grupları simfizin doğrusal genişlik ölçümleri bakımından değerlendirildiğinde hiperdiverjan bireylerden hipodiverjan bireylere doğru gidildikçe üst simfiz genişliğinin (B-B') ve alt simfiz genişliğinin (Pg-Pg') arttığı görülmüştür.

Sınıf I hiperdiverjan bireylerden hipodiverjan bireylere doğru gidildikçe simfiz mental açısındaki artış ve simfiz eğimindeki artış, hipodiverjan bireylerde simfiz genişliğininin artış1 ile sonuçlanmıştır. Bulgularımız literatür ile uyumludur (28). Buna karşılık Şahin, iskeletsel Sinıf I yapıya sahip hiperdiverjan, normodiverjan ve hipodiverjan gruplar arasında Pg’MePg ölçüm değeri bakımından istatistiksel olarak anlamlı farklılığın olmadığını rapor etmişlerdir (27). Bulgularımızdan farklı olan bu sonucun nedeni, çalışmaya dâhil edilen bireylerde ideal overjet ve overbite ilişkisinin sağlanmasına yönelik dentoalveoler kompanzasyonun işlev görmemesi olabilir.

İdeal overjet-overbite ilişkisine sahip Sınıf I, tüm gruplarda hiperdiverjan bireylerden hipodiverjan bireylere doğru azalma gösteren tek açı, IdoBoMe açısıdır. Hipodiverjan bireylerde simfizin daha kısa ve iç eğim açısının azalmasıyla birlikte daha kıvrımlı, buna karşılık hiperdiverjan bireylerde simfizin özellikle üst kaidesi olmak üzere daha uzun ve düzleşme eğilimindedir. Farklı dik yön boyutlarına sahip bireyler arasında gerek simfiz yüksekliği, gerekse simfizin mandibular kaide ile olan açısal ilişkisini belirleyen faktörün simfizin üst ve alt kaideleri arasındaki açı (IdoBoMe) olduğu, bu açısal değişiklikten sorumlu en önemli faktörün ise orofasiyal kas zinciri olabileceği düşünülebilir (29).

\section{Sonuç}

İdeal overjet ve overbite' 11 farklı dik yön boyutlarına sahip Sınıf I bireylerde, yüzün dik yön boyutları arttıkça alt ve üst keserler kendi kaidelerine göre daha retrüziv, arka yüz yüksekliklerindeki artışla daha protrüziv konumlanmışlardır.

Keserler arası açı dik yön değişikliğinden etkilenmemiştir.

Dik yön boyutları arttıkça alt ve üst keserler ekstrüze olmuş, maksiller ve mandibuler anterior alveoler bazal kemik yüksekliği artmıştır. 
Sınıf I hiperdiverjan bireylerde simfiz arka yüzeyi daha düz ve sı̆̆ Sınıf I hipodiverjan bireylerde ise, daha eğimlidir. Sınıf I hiperdiverjan bireylerde ön açık kapanış oluşumunun engellenmesinde, simfizin üst yüksekliğindeki artışın etkin rol oynamaktadir.

\section{Teşekkürler}

$\mathrm{Bu}$ araştırma Süleyman Demirel Üniversitesi Bilimsel Araştırma Projeleri Koordinasyon Birimi tarafından 4133-

D1-14 proje numarası ile desteklenmiştir.

\section{Kaynakça}

1. Solow B. The dentoalveolar compensatory mechanism: background and clinical implications. Br J Orthod. 1980; 7:145-61.

2. Betzenberger D, Ruf S, Pancherz H. The compensatory mechanism in high-angle malocclusions: a comparison of subjects in the mixed and permanent dentition. Angle Orthod. 1999; 69:27-32.

3. Kuitert R, Beckmann S, van Loenen M, Tuinzing B, Zentner A. Dentoalveolar compensation in subjects with vertical skeletal dysplasia. Am J Orthod Dentofacial Orthop. 2006; 129:649-57.

4. Casko JS, Sheperd WB. Dental and skeletal variation within the range of normal. Angle Orthod. 1984;54:5-17.

5. Anwar N, Fida M. Compensation for vertical dysplasia and its clinical application. Eur J Orthod. 2009; 31:516-22.

6. Kucera J, Marek I, Tycova H, Baccetti T. Molar height and dentoalveolar compensation in adult subjects with skeletal open bite. Angle Orthod. 2011; 81:564-9.

7. Bjork A, Skieller V. Normal and abnormal growth of the mandible. A synthesis of longitudinal cephalometric implant studies over a period of 25 years. Eur J Orthod. 1983; 5:1-46.

8. Beckmann SH, Kuitert RB, Prahl-Andersen B, Segner D, The RP, Tuinzing DB. Alveolar and skeletal dimensions associated with overbite. Am J Orthod Dentofacial Orthop. 1998; 113:443-52.

9. Ishikawa H, Nakamura S, Iwasaki H, Kitazawa S, Tsukada $\mathrm{H}$, Sato Y. Dentoalveolar compensation related to variations in sagittal jaw relationships. Angle Orthod. 1999; 69:534-8.

10. Bishara SE, Jakobsen JR. Longitudinal changes in three normal facial types. Am J Orthod. 1985; 88:466-502.

11. Bibby RE. Incisor relationships in different skeletofacial patterns. Angle Orthod. 1980; 50:41-4.

12. Isaacson RJ, Speidel TM, Worms FW. Extreme variation in vertical facial growth and associated variation in skeletal and dental relations. Angle Orthod. 1971; 41:219-29.

13. Schudy FF. Cant of the occlusal plane and axial inclinations of teeth. Angle Orthod. 1963; 33:69-82.

14. Bishara SE, Jakobsen JR. Longitudinal changes in three normal facial types. Am J Orthod. 1985; 88:466-502.

15. Hering K, Ruf S, Pancherz H. Orthodontic treatment of openbite and deepbite high-angle malocclusions. Angle
Orthod. 1999; 69:470-7.

16. Klocke A, Nanda RS, Kahl-Nieke B. Anterior open bite in the deciduous dentition: longitudinal follow-up and craniofacial growth considerations. Am J Orthod Dentofacial Orthop. 2002; 122:353-8.

17. Lopez-Gavito G, Wallen TR, Little RM, Joondeph DR. Anterior open-bite malocclusion: a longitudinal 10-year postretention evaluation of orthodontically treated patients. Am J Orthod. 1985; 87:175-86.

18. Siriwat PP, Jarabak JR. Malocclusion and facial morphology is there a relationship? An epidemiologic study. Angle Orthod. 1985; 55:127-38.

19. Nahoum HI. Vertical proportions and the palatal plane in anterior open-bite. Am J Orthod. 1971;59:273-82.

20. Schudy FF. Vertical growth versus anteroposterior growth as related to function and treatment. Angle Orthod. 1964; 34:75-93.

21. Gazilerli Ü, İşcan HN. Değişik cins ve iskeletsel sinıflamalarda Holdaway yumuşak doku ölçümlerinin değişimi. Ankara Üniversitesi Diş Hekimliği Fakültesi Dergisi. 1980;7:167-74.

22. Katsaros C, Berg R. Anterior open bite malocclusion: a follow-up study of orthodontic treatment effects. Eur J Orthod. 1993; 15:273-80.

23. Fields HW, Proffit WR, Nixon WL, Phillips C, Stanek E. Facial pattern differences in long-faced children and adults. Am J Orthod. 1984; 85:217-23.

24. Açıkbaş A. Dik Yön Boyutlarının Değişimine Göre Yüzün Kompanzasyonel Gelişiminin Longitudinal Olarak İncelenmesi. Ankara Üniversitesi Sağlık Bilimleri Enstitüsü Ortodonti Anabilim Dalı, Doktora Tezi, 1992.

25. Gülsüm Y. Farklı Vertikal Yön Yüz Gelișimine Sahip Genç Erişkin Bireylerde Yüz Oranlarının Sefalometrik Olarak İncelenmesi. Atatürk Üniversitesi Sağlık Bilimleri Enstitüsü Ortodonti Anabilim Dalı, Doktora Tezi, 2008.

26. Al-Khateeb SN, Al Maaitah EF, Abu Alhaija ES, Badran SA. Mandibular symphysis morphology and dimensions in different anteroposterior jaw relationships. Angle Orthod. 2014; 84:304-9.

27. Şahin-Selçuk A. İskeletsel Sınıf I Yapıya Sahip Bireylerde Yüzün Vertikal Yönde İncelenmesi. Ankara Üniversitesi Sağlık Bilimleri Enstitüsü Ortodonti Anabilim Dalı, Doktora Tezi, 1992.

28. Aki T, Nanda RS, Currier GF, Nanda SK. Assessment of symphysis morphology as a predictorof the direction of mandibular growth. Am J Orthod Dentofacial Orthop. 1994; 106:60-69.

29. Öz U. Farklı Rotasyon Modellerine Sahip Sinıf II, 1 Maloklüzyonlu Bireyler ile Sinıf I Bireyler Arasındaki Dentoalveoler ve Kraniyofasiyal Yap1 Farklılıklarının Değerlendirilmesi. Ankara Üniversitesi Sağlık Bilimleri Enstitüsü Ortodonti Anabilim Dalı, Doktora Tezi, 2009. 